\title{
Study of environmental safety of construction ceramics produced using anthropogenic waste
}

\author{
Elizaveta Pavlycheva ${ }^{1}$, Evgeniy Pikalov ${ }^{1}$, and Oleg Selivanov ${ }^{{ }^{*}}$ \\ ${ }^{1}$ Vladimir State University named after A.G. and N.G. Stoletovs', Gor'kogo, 87, 600000, Vladimir, \\ Russia
}

\begin{abstract}
The study presents the research results confirming environmental safety of the ceramic material used for construction purposes, produced basing on low-plasticity clay from the Vladimir region with the introduction of $2.5 \mathrm{wt}$. \% boric acid, 5 wt. \% of electroplating sludge and $30 \mathrm{wt}$. $\%$ of cullet. The material environmental safety has been previously confirmed by Daphnia mortality method in diurnal water extracts from the chipped ceramic material samples, including possible mechanical damage and deterioration during the operation. The experimental studies embraced the determination of heavy metal ions concentration in diurnal extracts from the chipped ceramic material samples in neutral and acidic media. Additional studies dealing with the heavy metals migration into the extracts were carried out in static mode during 20 days. The research results confirm the environmental safety of ceramic material in neutral and acidic media during the heavy metals immobilization, caused by ceramics self-glazing and vitrification. The research results proved that the production of the developed material will expand the regional raw material base, will contribute to the utilization of large-capacity and toxic waste with simultaneous manufacturing of highquality and environmentally friendly construction products for new buildings construction or existing buildings and structures reconstruction.
\end{abstract}

\section{Introduction}

Environmental safety is one of the principle characteristics of materials and products, including those used in construction, and implies no harmful effect for humans and environment throughout the entire operation period. The development of human society and industrial production provided alongside completely environmentally friendly materials such as wood, stone, straw, clay and sand, wider application of such materials and components as bitumen, cement, polymer resins, heavy metal salts, which refer to environmentally harmful and toxic substances or even become dangerous if environmental, technical and sanitary requirements for their application are neglected.

It causes environmental pollution during production, operation and waste accumulation, so recently, technologies for the environmentally friendly materials production and

\footnotetext{
* Corresponding author: selivanov6003@mail.ru
} 
technologies for waste recycling, both safe and toxic, have become increasingly wide spread.

The simplest and most effective method of recycling waste into the environmentally friendly materials is their consumption in the construction materials production [1-3]. Ceramic, cement and polymer composite materials are the most promising among all the construction materials, regarding the usage of waste as additives for various purposes [4-6].

It depends on the wide variety of these materials in composition, structure and properties, thus expanding their operational performance, application areas and conditions. Herewith, waste recycling technologies for producing environmentally friendly high-quality materials are particularly urgent, as they allow reducing the accumulated waste amount and primary resources consumption. During the production of such materials, comprehensive studies are necessary to confirm their environmental safety.

The research authors have previously developed the ceramic material based on lowplasticity clay from the Vladimir region with the introduction of $2.5 \mathrm{wt}$. \% boric acid, 30 wt. $\%$ of cullet and 5 wt. $\%$ of electroplating sludge [7]. The ceramic material production allows manufacturing products, characterized by high performance properties using lowdemand low-plasticity clay and simultaneously disposing large-capacity glass waste $[8,9]$ and toxic electroplating sludge, which processing is labor-intensive and long-term [10, 11]. The previous studies stated that Daphnia magna Straus mortality rate under the influence of toxic substances present in the diurnal water extract from the studied samples in 96 hours was detected not to exceed the established critical value of $50 \%$ [7], which is provided by the combined action of additives: cullet acts as vitreous phase source, and boric acid increases its amount and reduces the forming temperature. It is worth mentioning that this effect can be achieved using other glass-forming additives, such as titanium dioxide [12], lanthanum oxides [13], cerium [14] and molybdenum [15]. As a result, the vitreous phase formed during firing, which increases strength and frost resistance, includes heavy metal compounds, almost completely eliminating the possible migration of heavy metals into the aqueous media. However, potential heavy metals migration might occur when long term contacting both aqueous and acidic media.

Thus the research objective was to study the heavy metals migration from the developed ceramic material into the neutral and acidic water media during different study periods.

\section{Materials and methods}

In this research the low-plasticity clay of Suvorotskoye deposit in the Vladimir region of the following composition was applied (wt. \%): $\mathrm{SiO}_{2}=67.5 ; \mathrm{Al}_{2} \mathrm{O}_{3}=10.75 ; \mathrm{Fe}_{2} \mathrm{O}_{3}=5.85$; $\mathrm{CaO}=2.8 ; \mathrm{MgO}=1.7 ; \mathrm{K}_{2} \mathrm{O}=2.4 ; \mathrm{Na}_{2} \mathrm{O}=0.7$. The clay plasticity index, determined by the standard method, equals 5.2, therefore, in compliance with GOST 9169-75, this clay is lowplastic. Sheet window glass of the following composition was used as cullet (in wt.\%): $\mathrm{SiO}_{2}$ $=73.5 ; \mathrm{CaO}=7.4 ; \mathrm{MgO}=1.9 ; \mathrm{Na}_{2} \mathrm{O}=11.1 ; \mathrm{K}_{2} \mathrm{O}=5.2 ; \mathrm{Al}_{2} \mathrm{O}_{3}=0.9$. Galvanic sludge, formed as a result of effluent reagent treatment at the Avtopribor plant (Vladimir), and characterized by the following composition (wt. \%): $\mathrm{Zn}(\mathrm{OH})_{2} \approx 11.3 \%$; $\mathrm{SiO}_{2} \approx 7.08 \%$; $\mathrm{Ca}(\mathrm{OH})_{2} \approx 16.52 \% ; \mathrm{Cr}(\mathrm{OH})_{3} \approx 9.31 \% ;\left(\mathrm{Fe}^{2+}\right) \mathrm{Cr}_{2} \mathrm{~S}_{4} \approx 4.17 \% ; \mathrm{CaCO}_{3} \approx 40.25 \% ; \mathrm{CaO} \approx$ $3.45 \% ; \mathrm{ZnO} \approx 2.41 \% ; \mathrm{Cu}(\mathrm{OH})_{2} \approx 2.38 \% ; \mathrm{Ni}(\mathrm{OH})_{2} \approx 2.62 \% ; \mathrm{Mn}(\mathrm{OH})_{2} \approx 0.64 \% ; \mathrm{Pb}(\mathrm{OH})_{2} \approx$ $0.14 \%$ was introduced into the charge. Additionally boric acid grade B 2nd class (GOST 18704-78) was introduced [7].

To produce the samples from the studied ceramic material, clay, cullet and electroplating sludge were pre-dried to a constant mass and crushed and selected fraction of max particle size $0.63 \mathrm{~mm}$. Afterwards all the charge components were mixed dry at the specified ratios and with $5 \mathrm{wt}$ \% of water addition to make homogeneous molding mass for 
producing ceramic samples at $15 \mathrm{MPa}$ pressing pressure and maximum firing temperature of $1050^{\circ} \mathrm{C}$.

The density $\left(\rho, \mathrm{kg} / \mathrm{m}^{3}\right)$, compressive strength $\left(\sigma_{\mathrm{cmp}}, \mathrm{MPa}\right)$, porosity $(\mathrm{P}, \%)$, water absorption (WA,\%), and frost resistance (FR, cycles) have been determined for the studied ceramics samples in compliance with the standard methods for construction ceramics. The ceramics preliminary environmental safety has been assessed applying the method for determining Daphnia magna Straus mortality under the toxic substances impact in the diurnal water extract from the studied samples.

The migration of heavy metals contained in the electroplating sludge in highest concentrations (zinc, chromium, copper and Nickel) into the diurnal water and ammoniumacetate extracts were tested applying the samples with chipped surfaces, which allow taking into account the possible mechanical damage and wear of the products during operation. The atomic absorption spectrometer "Quant-Z ETA-T" (Kortek LLC, Moscow) was used to obtain numerical indicators of heavy metal migration into the simulated media.

\section{Results}

To assess the components impact on the material properties and its environmental safety, the experiments have been conducted with the samples based on the compositions presented in Table 1.

Table 1. Charge compositions under the stud.

\begin{tabular}{|c|c|c|c|}
\hline \multirow{2}{*}{ Composition № } & \multicolumn{3}{|c|}{ Additives content, mass \% } \\
\cline { 2 - 4 } & GSh & SB & BK \\
\hline 1 & - & - & - \\
\hline 2 & 5 & 30 & 2.5 \\
\hline 3 & 5 & 30 & 5 \\
\hline 4 & 10 & 30 & 2.5 \\
\hline
\end{tabular}

Table 2 presents the determination results of the physical and mechanical properties and preliminary assessment of the samples environmental safety produced basing on the charge compositions given Table 1.

Table 2. Physical and mechanical properties and environmental safety of the studied ceramics.

\begin{tabular}{|c|c|c|c|c|c|c|}
\hline $\begin{array}{c}\text { Composition } \\
\text { № }\end{array}$ & $\rho, \mathrm{kg} / \mathrm{m}^{3}$ & $\begin{array}{c}\sigma_{\mathrm{cmp}}, \\
\mathrm{MPa}\end{array}$ & $\mathrm{R}, \%$ & $\mathrm{WA}, \%$ & FR, cycles & $\begin{array}{c}\text { Daphnia } \\
\text { mortality } \\
\text { in 96 h, \% }\end{array}$ \\
\hline 1 & 2099.4 & 14.3 & 6.9 & 7.5 & 41 & 0 \\
\hline 2 & 1687.0 & 29.4 & 3.0 & 3.1 & 51 & 20 \\
\hline 3 & 1865.6 & 17.7 & 2.8 & 2.9 & 51 & 50 \\
\hline 4 & 1764.8 & 14.3 & 3.4 & 3.6 & 39,1 & 80 \\
\hline
\end{tabular}

The received data reveals that initial ceramics produced without any additives is characterized by poor properties and environmental safety. The increased amount of electroplating sludge worsens the ceramics performance due to the pore-forming effect and reduces its environmental safety due to the heavy metals presence. Boric acid increases the 
ceramics performance due to the flux-strengthening effect and, besides, its large quantities cause the environmental safety reduction due to the certain toxicity of boric acid.

Further experimental results (see Table. 3) for the samples, based on compositions 2-4, the heavy metals concentrations in diurnal extracts during their migration into the neutral media are significantly lower than threshold limit values (TLV) established in regulatory documents ([12] GN 2.1.5.1315-03, Russia). The heavy metals concentrations in diurnal extracts during their migration into acidic environments also do not exceed the TLV established by regulatory documents, but nickel concentrations for the samples, based on compositions 2 and 3, approach the threshold level, and for the samples based on composition 4, it exceeds TLV for nickel.

Table 3. Determination of heavy metals migration in to the simulated media.

\begin{tabular}{|c|c|c|c|}
\hline \multirow[t]{2}{*}{ Metal } & \multicolumn{2}{|c|}{ Metal concentration, $\mathrm{mg} / \mathrm{l}$} & \multirow{2}{*}{$\begin{array}{l}\text { TLV for metals water bodies } \\
\text { for economic, drinking } \\
\text { application, } \mathrm{mg} / \mathrm{l}\end{array}$} \\
\hline & $\begin{array}{c}\text { in distilled } \\
\text { water extract } \\
(\mathrm{pH}=7.2)\end{array}$ & $\begin{array}{l}\text { in ammonium- } \\
\text { acetate extract } \\
(\mathrm{pH}=4.8)\end{array}$ & \\
\hline \multicolumn{4}{|c|}{ Composition 2} \\
\hline Zinc & 0.031 & 0.182 & 1 \\
\hline Chromium & 0.006 & 0.028 & 0.5 for $\mathrm{Cr}^{3+}$ \\
\hline Nickel & 0.004 & 0.082 & 0.1 \\
\hline Copper & 0.001 & 0.146 & 1 \\
\hline \multicolumn{4}{|c|}{ Composition 3} \\
\hline Zinc & 0.026 & 0.125 & 1 \\
\hline Chromium & 0.004 & 0.017 & 0.5 for $\mathrm{Cr}^{3+}$ \\
\hline Nickel & 0.003 & 0.061 & 0.1 \\
\hline Copper & 0.001 & 0.104 & 1 \\
\hline \multicolumn{4}{|c|}{ Composition 4} \\
\hline Zinc & 0.085 & 0.345 & 1 \\
\hline Chromium & 0.014 & 0.071 & 0.5 for $\mathrm{Cr}^{3+}$ \\
\hline Nickel & 0.009 & 0.165 & 0.1 \\
\hline Copper & 0.004 & 0.292 & 1 \\
\hline
\end{tabular}

In this regard, it has been decided to continue the experiments concerning the heavy metals migration from the test material samples into the extracts in static mode during 20 days to assess the environmental safety more accurately.

The research results have demonstrated (see Fig. 1-6) that the samples based on compositions 2-4 revealed the greatest concentration increase of the considered heavy metals during the first three days. Such dependence is explained by the fact that primarily migration occurs from the surface layers of the ceramic material. After the first two days, the migration rate significantly decreases, since the migration is affected by the heavy metal ions diffusion rate from the inner layers of the studied material. 


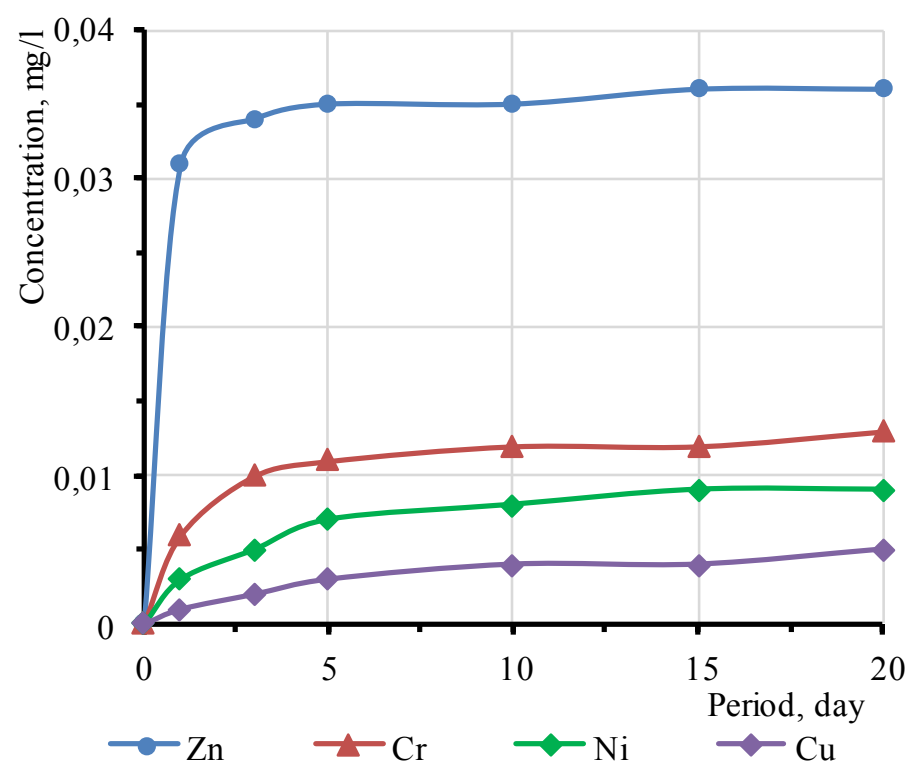

Fig. 1. Dependence of heavy metal ions concentration in distilled water solution on exposition period for samples, based on composition 2.

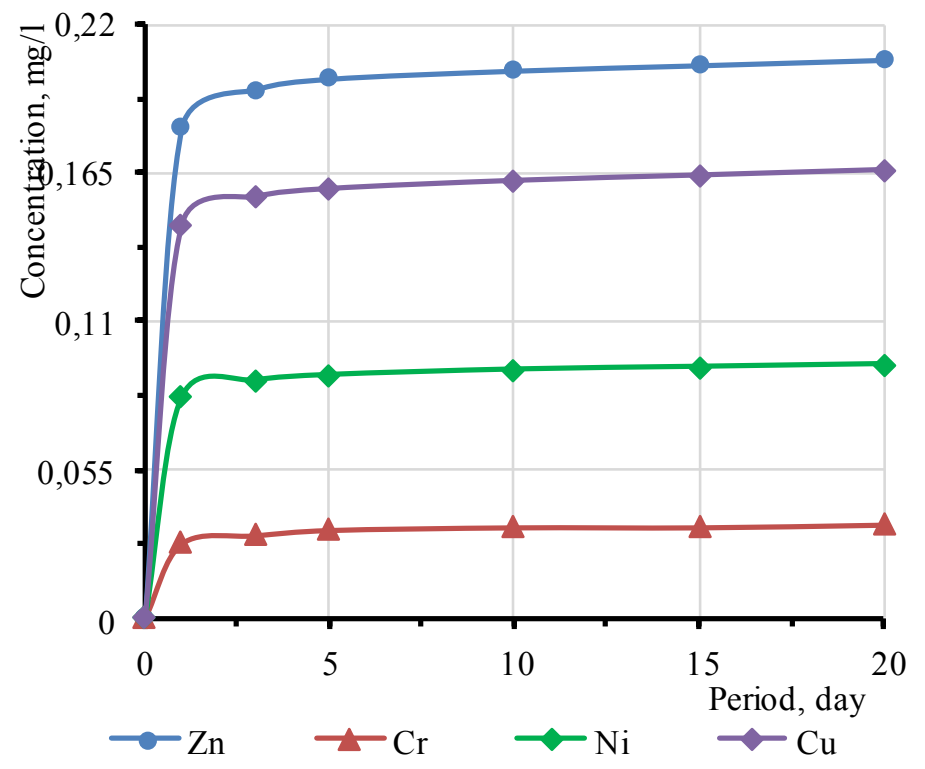

Fig. 2. Dependence of heavy metal ions concentration in ammonium-acetate buffer solution on exposition period, based on composition 2 . 


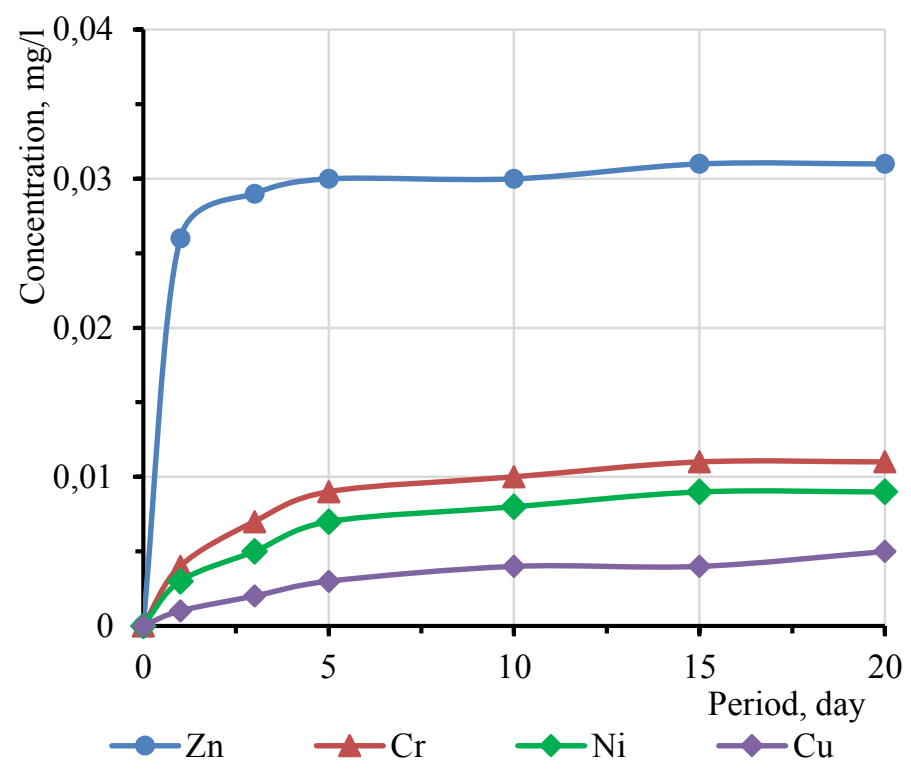

Fig. 3. Dependence of heavy metal ions concentration in distilled water solution on exposition period for samples, based on composition 3 .

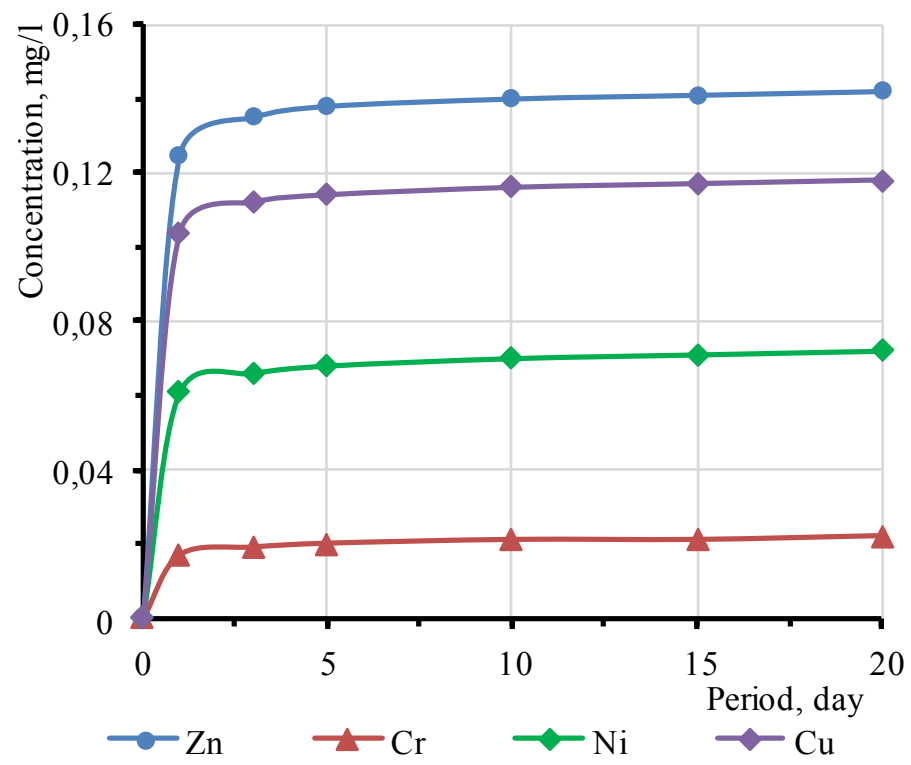

Fig. 4. Dependence of heavy metal ions concentration in ammonium-acetate buffer solution on exposition period, based on composition 3 . 


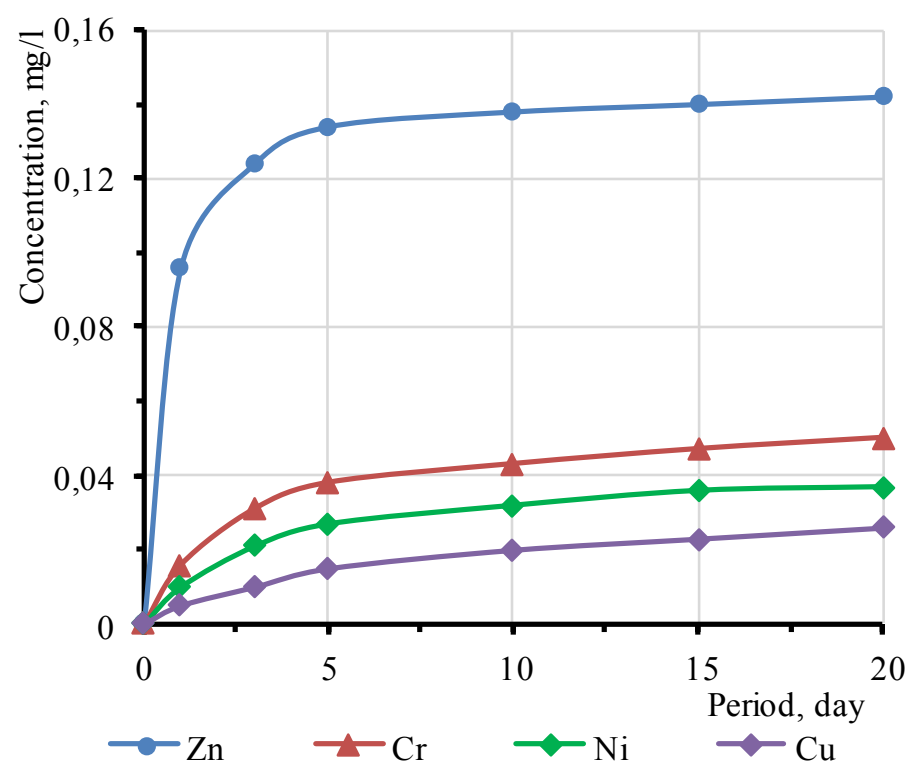

Fig. 5. Dependence of heavy metal ions concentration in distilled water solution on exposition period for samples, based on composition 4.

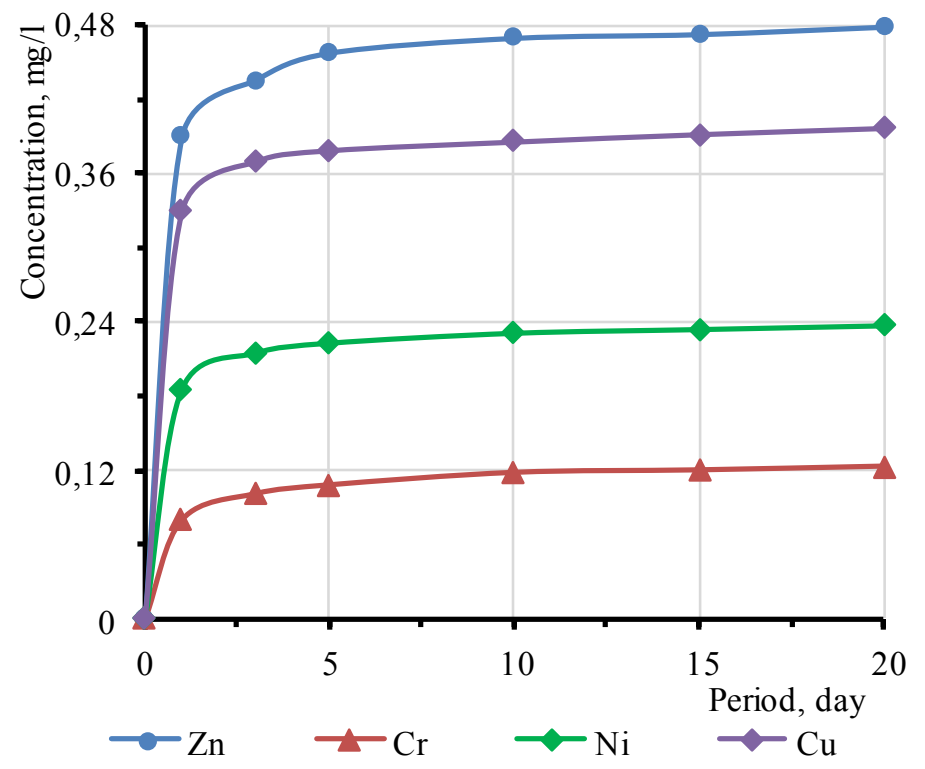

Fig. 6. Dependence of heavy metal ions concentration in ammonium-acetate buffer solution on exposition period, based on composition 4 .

The received data also indicate that the concentration of the considered heavy metal ions for the samples based on compositions 2 and 3 does not exceed the regulated permissible values during the entire experimental period. The concentration of the heavy metal ions for the samples based on composition 4, does not exceed TLV during the entire 
experimental period for the extracts but for the nickel ions migration into the acidic media, exceeding TLV by 2 times approximately.

Judging by the research results concerning Daphnia death, boric acid and its concentration increase can be concluded to contribute to the vitreous phase formation immobilizing heavy metals. However certain toxicity of boric acid, determined earlier (see Table 2), does not allow classifying the ceramics, based on composition 3, as environmentally safe, and, consequently, this component amount should be limited to 2.5 wt. \% for the studied charge compositions. The experimental results of the samples, based on composition 4 lead to the conclusion that safe amount of boric acid along the large amounts of galvanic sludge does not effectively immobilize heavy metals, thus causing drastic increase in their migration rate and the threshold level for nickel is exceeded during migration to acidic environments for the studied galvanic sludge. Taking into account the studies of Daphnia death the samples, based on composition 4, cannot be considered environmentally safe.

Consequently, the availability of vitreous phase in the material makes it possible to immobilize heavy metals effectively and to produce environmentally safe ceramics, using toxic waste.

\section{Conclusions}

According to the research results the ceramic material produced from the low-plasticity Thus, the research results prove that environmental safety of the developed construction ceramics under study is ensured in both neutral and acidic media. It is especially important, considering that the products might be affected by acid rain, and the foundation and plinth products are exposed to soil acidity.

Environmental safety in this study is ensured by the combined application of cullet and boric acid, which create the self-glazing effect of the product surface and glazing of the ceramic particles surface. Thus heavy metals are effectively immobilized, being either a part of the vitreous phase, making it more durable and chemically resistant, or being in the composition of crystalline mineral phases, which appear to be isolated from the external impact of the vitreous phase.

Consequently, the studied ceramic items allow complex utilization of anthropogenic waste in the Vladimir region, and low-plasticity clay application for producing high-quality and environmentally friendly products for the new construction or existing buildings and structures reconstruction.

\section{References}

1. M. Vidaurre-Arbizu, S. Pérez-Bou, A. Zuazua-Ros, C. Martín-Gómez, Journal of Cleaner Production, 291, 125960 (2021)

2. H.A. Abdel-Gawwad, A.M. Rashad, M.S. Mohammed, T.A. Tawfik, Journal of Building Engineering, 42, 102479 (2021)

3. D. Simón, S. Gass, C. Palet, A. Cristóbal, Journal of Building Engineering, 40, 102371 (2021)

4. P.N. Lemougna, J.Yliniemi, H. Nguyen, E. Adesanya, P. Tanskanen, P. Kinnunen, J. Roning, M. Illikainen, Journal of Building Engineering, 31, 101383 (2020)

5. L. Li, W. Liu, Q. You, M. Chen, Q. Zheng, Journal of Cleaner Production, 259, $120853(2020)$ 
6. A.D. La Rosa, S.A. Grammatikos, G.A. Ursan, S. Aradoaei, J. Summerscales, R.C. Ciobanu, C.M. Schreiner, Journal of Cleaner Production, 280(2), 124593 (2021)

7. Vitkalova I., Torlova A., Pikalov E., Selivanov O., E3S Web of Conferences, 33, 02062 (2018) doi.org/10.1051/e3sconf/20183302062

8. F. Heriyanto, V. Pahlevani, V. Sahajwalla, Journal of Cleaner Production, 191, 192206 (2018)

9. A. Adediran, P.N. Lemougna, J. Ylinieme, P. Tanskannen, P. Kinnunen, J. Roning, M. Illikainen, Journal of Cleaner Production, 289, 125673 (2021)

10. F.M. Pinto, R.A. Pereira, T.M. Souza, A.A. Saczk, Z.M. Magriotis, Journal of Environmental Management, 280, 111706 (2021)

11. L. Pérez-Villarejo, S. Martínez-Martínez, B. Carrasco-Hurtado, D. Eliche-Quesada, C.Ureña-Nieto, P.J. Sánchez-Soto, Applied Clay Science, 105-106, 89-99 (2015)

12. A.A. Vorobeva, V.N. Shakhova, E.S. Pikalov, O.G. Selivanov, E.P. Sysoev, V.Yu. Chukhlanov, Glass and Ceramics, 75(1-2), 51-54 (2018)

13. I. Vitkalova, A. Torlova, E. Pikalov, O. Selivanov, MATEC Web of Conferences, 193, 03035 (2018) doi.org/10.1051/matecconf/201819303035

14. I. Vitkalova, A. Uvarova, E. Pikalov, O. Selivanov, Advances in Intelligent Systems and Computing, 1259, 457-463 (2021)

15. A.S. Torlova, I.A. Vitkalova, E.S. Pikalov, O.G. Selivanov, Glass and Ceramics, 76, 419-422 (2020) 